\title{
AN ONLINE SEMI-STRUCTURED APPROACH TO HELPING STUDENTS MAKE THE MOST OF PROJECT-BASED LEARNING (PBL)
}

\author{
Marwan Elmubarak \\ Assistant Professor (Ph.D., AIA.) United Arab Emirates University, UAE, \\ [Marwan.elmubarak@uaeu.ac.ae]
}

\begin{abstract}
Project-Based Learning (PBL) typically provides students of urban planning with opportunities to apply knowledge and to synthesize different topics relevant to the context of the area they are studying. As higher education institutions increasingly adjust to online and blended learning, there is a need to reconsider how Project-Based Learning (PBL) can be realized in a fully designed online courses or in those utilizing blended learning methods. This paper considers the opportunities and challenges online platforms present to projectbased learning by reflecting on the author's experience with PBL and blended learning techniques he has developed for two urban planning, blended learning courses over the last five semesters. The techniques were repeatedly applied and incrementally adjusted as needed from one semester to the next in response to the instructor's critical evaluation and students' feedback. The article reports on lessons learnt and details a semi-structured approach to helping students engage effectively while allowing the instructor to assume more coaching and mentoring roles to facilitate the learning. It also reflects on the efficacy of using certain online Apps to increase the effectiveness of Project-Based Learning (PBL) for students' team projects- both in terms of learning by students, as well as supervising, mentoring and evaluating by the instructor. Students reported benefiting from the approach in several ways including the timely feedback they receive, the personalized pacing and the ability to manage their project as they progress.
\end{abstract}

Keywords: Project-Based Learning, Urban Planning Education, Online Approaches, Blended Learning, Team-Based Learning.

\section{INTRODUCTION}

Project-based learning (PBL) is one of the key educational strategies that offer students opportunities to synthesize and apply knowledge, as well as become independent learners and thinkers. It is a studentcentered approach to learning with the added advantage of giving students opportunities to develop soft skills, apply theory to practice, and develop critical thinking and problem-solving skills. It has long been advocated in high quality undergraduate programs, particularly those with disciplines that prepare students for careers in certain professions (Boyer, 2018; Shepherd et al. 1998). Urban planning, the subject of this article, is one such discipline. For urban planning undergraduate programs, students are expected to finish core courses that blend theoretical topics with practice-oriented applications where the goal is to initiate students for an effective professional life as they finish the program and graduate. In these courses, projectbased learning is fundamental, as it affords the students opportunities for 'learning by doing'; a phrase first 
coined by the famous education reformer and philosopher John Dewey in the last century, and was later adopted to urban planning education by a number of scholars, including Schon (1983), and Ives-Dewey (2009). Schon (1983), for instance, suggested that projects assignments for urban planning students require a specific method of teaching, or more specifically coaching which he termed reflective learning, in which the teacher assumes the role of a mentor and a facilitator. Schon's ideas of reflective learning highlight an important aspect to learning, particularly that of the student-teacher interactions, where the student is actively involved in responding to specific problem or project requirements while getting constant feedback and response from the teacher who assumes the role of a 'coach' and facilitator. The success of such learning process thus, hinges on the presence of effective communication on the part of all participants (Susskind et al. 1984). However, to realize positive results, this type of teaching needs to be designed such that there is an effective and well-thought out approach to guide the process. The instructor should be able to communicate ground rules for this process from the onset of the project (Boyer, 2018; Michaelson e al., 2008). Project-based and team-based learning are often cited among the best strategies to achieve effective experiential learning. However, while there is agreement on the significance of team projects in helping students reap the benefits of experiential learning, on the aggregate, actual practices and experiences of both students and faculty continue to fall below expectations.

As with the case with similar programs, the core courses of the undergraduate urban planning program at United Arab Emirates University (UAEU) typically mix theory and practice topics and provide students with experiences of project-based learning so that they get to establish linkages, recognize relationships, and apply knowledge in more concrete ways. In principle these projects are expected to significantly enhance students learning, particularly if they involve a high degree of independence and experiential learning, and especially if there is a clear and active role played by the instructor in the way of facilitating, mentoring, and monitoring students' efforts as the process unfolds. However, actual practice of project-based learning is not without challenges. Instructors conducting these courses, have increasingly reported mixed results. Often instructors note difficulties in mentoring students' teams that are doing team-based projects, mainly due to the minimum opportunities for interval assessment or due to lack of consistent communication with the participating students (Boyer, 2018; Neu, 2012). From the student's perspective mixed evaluations are often cited as well (Greenlee et al. 2015, Johnson et al., 2014)). While many students report that projects enhanced their learning, making them more appreciative of their country or city local context, as seen through the lens of the course material, others reported challenges with the process of team projects. These are noted to include issues having to do with group dynamics and different individual personalities, and often lack of leadership on the part of the team members, which lead to dependence on one or two active individuals completing the exercise while others in the team are getting rewarded with the same grade (Aggarwal et al. 2008; Belwal et al. 2020; Konrad et. al. 2020). Further, good students often bring up the issue of fairness if project assessment rewarded all students equally (Sherrad et al. 1994). Assessing team members equally often has negative implications as it may prompt performing students to desire to work individually in future projects rather than collaborating in a team with other students. Moreover, students often feel uncomfortable to report on fellow teammates who are engaged the least, which makes assessing each team member individually a real challenge. Even if students spoke on other team members, their reporting might not be conclusive or genuine enough for the instructor to conclude a certain assessment, which makes it necessary to conduct additional investigation and verification before making a final judgement. Yet, the learning experience can seriously be undermined if this is the case, for such actions can result in further unintended consequences including low morale, lack of trust among team members and weakened enthusiasm for teamwork (Konrad et al., 2020). This is probably among the top reasons why students with high sense of responsibility and propensity for honest and active performance often ask to be exempted from working in groups. The instructor then is left with the dilemma of convincing students that doing the work in teams is essential part of the exercise. Nonetheless, and at a minimum, the instructor should be firm in setting the ground rules at the onset of the project by emphasizing that collaboration and teamwork is a critical part of the project-based learning experience. Instructors also report challenges with team projects chief among which is their inability to be fully involved in facilitating the work and mentoring the students while the teams are conducting the project.

In this article the author presents his approach to addressing these issues, particularly the role of the instructor as a mentor. The study reports on the author's experience with implementing this approach in mainly two urban planning courses taught over five semesters and offered in a period of four academic consecutive years. Long before the onset of the circumstances created by COVID 19 that forced many educational institutions to adjust to online learning, the author has been blending part of his course offerings with online content and methods, utilizing state of the art educational technology platform available to UAEU faculty and students. Thus, he has been developing an online approach to bypass challenges of conventional project-based learning and to enhance the effectiveness of his role as an active mentor helping 
students in getting the most of project-based learning. The following sections introduce the two courses this approach was implemented in, discusses the online approach, and highlights the main steps in implementing the method. The article ends with conclusion as well as learning and reflections from both the students and the author.

\subsection{Project-Based Learning as a Form of Experiential Learning}

Debates on the appropriate learning strategies concerning the education of future planners present a common theme in planning education literature (e.g. Boyer, 2018; Brooks et al, 2002; Gu, 2018; Johnston, 2015; Matunga, 2017). One of the main concerns is the need to link theory to practice to enhance students' understanding, and to help them build a strong employability profile. The latter is often expressed as the need for graduates to develop a sense of the type of skills considered valuable in planning practice. Among these are written and oral communication and negotiation skills, analytical skills, and an understanding of the complexity and constraints of local contexts. Further, exposing students to real world problems where they can apply knowledge learnt in the classroom, exercise critical thinking skills, and synthesize different aspects of such knowledge has been strongly stressed as a valuable urban planning program objective ( Boyer, 2018). Teaching and learning strategies to help students acquire these skills are continually proposed. Kotval (2003) noted that the advantages of group learning are: communication and teamwork interaction skills, critical thinking skills, as well as the ability to synthesize knowledge and understand key planning issues. Team-based learning or collaborative learning has thus been advocated by many educators and practitioners (Greenlee et al, 2015; Long, 2012).

The importance of experiential learning in its many forms including studio experiences, team-based learning, and project-based learning is often highlighted as it is thought to allow for simulating real-world planning problems while affording the students the opportunity to develop the increasingly recognized soft skills of collaboration and team work (Boyer, 2018; Greene et al. 2015). However, the adoption and implementation of these strategies are not without challenges. Often their effective application is undermined by the fact that they can be relatively resource-intensive, requiring special schedules, particularly if instructors are expected to devote the necessary time needed for coaching and mentoring of students on an individual basis. Further, students often find the process slow and somewhat challenging specially if they happen to be working together for the first time. As noted by Boyer (2018), a reasonable degree of cohesiveness between student team members is highly critical. Lack of cohesiveness will lead to ineffective group interaction and ultimately poor learning experiences (Konrad et al.,2020). Therefore, it is vitally important for the instructor to be able to intervene early in the process so that such issues of cohesiveness can be resolved. This, however, can be a taxing exercise on both the instructor and the students particularly if conventional methods of mentoring and intervention continue to be followed. As suggested by Boyer (2018) one possible solution to the problem is by forming students' teams and creating opportunities for students to engage in teamwork, even if in small specific exercises, right from the beginning of the course. The author argues another approach to addressing the challenges discussed thus far, is through exploring the potential of educational technology and online applications. Education technology, as argued in this article, can offer ways to bypass such issues and thus enhance the learning experiences of students in ways that align with universities' institutional and programs' learning outcomes. What holds great promise for such approach is the fact that the current generation of students in urban planning programs are naturally inclined to using technology. Perhaps the real adjustment needs to originate from the institutions and the faculty teaching this technologically savvy generation.

\subsection{Method}

This study reports on a case study of two urban planning courses taught repeatedly over a period of four years at the undergraduate urban planning program at UAEU. The two courses are: a) Land Use Policy and Planning, and b) Urban and Regional Planning. The total number of students enrolled in each class is typically 30. The semi-structured method, the focus of this article, was used in 8 different class offerings over the four-year period, bringing the total number of students who experimented with this approach to 240 students. Students teams were limited to 3 students maximum. In helping students form teams, the author has come to the realization that for the context and circumstances of the students he is dealing with it is best to keep the team size at three participants maximum. This was precipitated by the fact that most of the students spend only four days per week at the university campus and are often transported back to their different cities on the fifth day. Limiting the number of students to three helped students in building a reasonable degree of cohesiveness than otherwise possible. Thus, the total number of teams the author has worked with over the five-semester period equaled 80 teams.

The author introduced the semi-structured online approach to facilitating students group meetings and for mentoring students as the process unfolds, mainly to help students better achieve the advantages of projectbased learning. The method primarily involved introducing students to the features of Microsoft 360, 
particularly Email Groups in Microsoft Outlook, the OneNote application, which is linked to it, as well as Microsoft Teams. The general idea of the approach is the utilization of these features in forming online groups dedicated for each team of three students, with the instructor being a participant and moderator in each of these students' email groups. Ultimately the objective is to enhance communication and create virtual meeting rooms where the individual teams can conveniently an privately meet yet have access to the instructor who can easily connect and communicate with each team through their dedicated online group. The reflections shared in this article are primarily of qualitative nature. That is, in addition to the author's critical reflection on the different five semesters in which this method was used, it also involved having open discussions with the students at the end of each semester in order to learn their assessment of their different experiences with this approach.

\section{CONTEXT OF THE STUDY}

The two courses of urban planning for which this online approach to project-based learning was developed and implemented are core courses in the urban planning program at UAEU. They combine both theory and practice topics. The first is Land Use Planning and Policy, and the second is Urban and Regional Planning. Both courses are considered upper level undergraduate courses the students can take after completing specific prerequisites. Further, the two courses reinforce each other, and the combined knowledge from taking them covers varied topics of urban planning and regional planning including sustainable development and land Use planning. They also together focus on issues of both policy and practice with a major part dedicated to addressing sustainability through the three-parts prism of environment, economy, and equity. Additionally, special emphasis is put on how to collect and analyze data used as input in the planning process such as economic, population and environmental data which inform land use planning decisions, and on issues of zoning, form-based codes and smart growth strategies.

In line with the university objectives and learning outcomes, when designing project assignments for these two courses two basic guiding principles were followed. First, the project main objective is to help students recognize and synthesize different course topics relevant to the chosen project title or focus. Second, the project should be of real-world nature and that it needs to be not only contextually relevant but also of a specific physical location or site within United Arab Emirates (UAE) cities. Typically, students are given the freedom to choose between developing their own proposal or solution to a particular planning problem, and studying an existing planning topic, issue, or site. In either of the two options, students are expected to develop an analytical and evaluative perspective utilizing the knowledge gained in class, conduct the necessary background research, and perform research tasks including application of primary research methods to gain data for their project. But more importantly, students are expected to work collaboratively in teams and build the highly valuable skills of collaboration and teamwork. These two courses presented the context and the case for this semi- structured approach that the author had the opportunity to study during the four-year period.

\section{THE SEMI-STRUCTURED ONLINE APPROACH}

In this section I introduce the approach to the online method in several steps starting with the protocol and ground rules of forming teams as well as helping students in the first team activity of project selection.

\subsection{Selecting Students' Teams}

Projects for these two classes are typically assigned toward the beginning of the fifth week in the semester. This is important because it gives the students time to develop familiarity with the class focus and helps them develop rapport and form acquaintances with classmates. However, the students' teams that will be conducting the class main project using the semi-structured approach are typically formed at the first week of the semester. This is important as it gives teams time to better know each other, develop cohesiveness, and become familiar with the class format. This effort can be further aided by getting these teams involved in small class assignments leading up to the kick-off date of the main project. As indicated in the method's section, typically, the enrollment ceiling for these two courses is 30 students each. Since the author's experience has shown that an optimum team size suitable for his students should not exceed three participants, this meant the instructor would always have 10 teams to work with, which proved to be a reasonable endeavor per semester particularly if he assumed the role of an active mentor and facilitator. This is due to the fact that teams consisting of three students maximum, are easier to manage and will make it difficult for the typically least performing students to maintain a low profile while the other members are doing the work. It is also easier for the instructor to monitor and know students by name, which builds trust if the instructor assumes the role of facilitator in a less forceful way. 


\subsection{Helping Students in Topics Selection}

Learning from previous experiences with team-based, project assignments, the instructor has had before developing this approach, he recognized that students always needed help in choosing a project topic. Many factors are the culprit here, including lack of confidence on the part of the students, unfamiliarity with the local context, conflicting schedules among students, and the time it takes to feel comfortable working with other team members ( Aggarwal et. al., 2008). As a result, valuable time, sometimes up to two weeks, ends up being consumed in the task of identifying a researchable topic. This highlights the need for providing students with a form or structure so that such decisions are not a source of frustration and confusion. However, providing structure should be done in as subtle way as possible so as not to leave the students with any misconceptions regarding the level of help they will get from the instructor. The instructor should guard against suggesting to the students that he will be doing their work for them. The appropriate approach thus is to provide a semi-structured framework for the students to operate on. This can begin with helping students in choosing general areas or themes for topics they can think of for their projects.

Therefore, one of the first tasks the instructor helps students with is the selection of a possible theme from which a researchable topic can be developed. To do this, the instructor prepares a list of twenty, or more, possible themes that the students can choose from, gives each theme a number, and distribute copies of the list among the ten project teams. Before getting the students selections, the instructor should spend enough time explaining the main idea for each theme and the possible ways it can be carried out as a project. It is highly critical that the suggested themes in the list be general in nature to give the students the flexibility to customize their selection to their interest or to a site they prefer to study. The instructor then, spends the class time in the first day of introducing the project addressing main ideas behind each theme and suggests possible ways students can focus it into a researchable topic or to possible local sites. The instructor at this point can also give initial hints of possible approaches to researching the idea. Students are invited to discuss and ask questions, even suggest their own modifications of certain themes that appeal to them. Instructor should carefully lead this process and hold off any criticism of ideas advanced by the students. Rather, he should strive to positively refine and build on the students' ideas if they seemed promising, as this will boost students' confidence, and elevate their interest and commitment to doing the exercise with the needed enthusiasm and energy.

Students then select a number from the instructor-provided list corresponding to the project theme of their preference. This step helps students to start communicating, and discussing options, and practically be in a project mode from day one, as it is the first time, they make their first decision together as a team. Also, it helps students to develop a degree of confidence and commitment, and their focus and energy will shift to thinking about the next steps. The instructor also affirms to the class that if none of the suggestions in the list is of interest to them, then they are not obliged to commit but should try to come up with a general idea of their choosing by the time the class meets again. The instructor also uses the balance of the class time to introduce the online method, explaining what his role in the process will be, and his expectations of the students.

\subsection{Microsoft 360, Outlook, OneNote and Microsoft Teams}

The online semi-structured approach used by the instructor with the students' project teams is primarily based on three online applications using Microsoft 360. The three applications are: OneNote; Outlook and Microsoft Teams. Prior to starting the students on the approach, the instructor should dedicate enough time introducing these online applications to the students. Students are generally already familiar if not savvy on the use of these readily available programs. Nonetheless, the instructor should spend time demonstrating the features in each platform that are more suited to the project-based and team-based learning. Outlook email groups for instance, will be the main media of interaction as each individual team of three members will be assigned a dedicated email group. The instructor is always the fourth member in the group allowing for easy access, monitoring, mentoring, and facilitating as students' work progresses. Students are also informed about the wisdom of having the instructor create the email group. The instructor, being the initiator of the email group, will maintain control for features such as keeping the group private, or adding new members. If these features are not controlled and monitored, then it is likely other participants may get involved which may undermine the integrity of the students work.

Email groups are linked to the OneNote application through the corresponding tab on the main page of each email group. Accessing OneNote in this way, always opens a session specifically dedicated to the project team through the assigned email group. As such, any work or activity done using this application automatically will be saved and linked to the specific email group. Further, OneNote provides a valuable feature for the instructor in that it records the name of person who is active and save her/his contribution to the ongoing project. While it is necessary to stress to the students the need to primarily work off the email 
group, as the main channel of communication, the instructor should offer other means of connecting even talking as a team with the instructor using Microsoft Teams on as needed basis. Microsoft Teams is one such platform that gives the students teams the opportunity to set up meetings among themselves and with the instructor to go over particular issues as they arise or to further discuss the development of project ideas or progress.

\subsection{The Online Approach and Platform}

As the teams and their project titles have been determined, the next step involves introducing the online method. In introducing the online approach, the instructor should make it very clear that the intent is to help the students have instant access to each other as well as to the instructor. Once launched, the students no longer would need to schedule time to physically meet with teammates or with the instructor. The instructor tells the 10 students' teams that conducting the project effectively and with the ability to have easy access to the instructor requires the creation of Email groups, a feature in the Microsoft Outlook email platform. The online platform will act as a continuously open discussion and meeting room which members can be notified of any new activity by a simple email. In other words, the online platform acts as the subtle structure that is needed to help both the students and the instructor meet on a regular basis. The instructor will always have access to each team. Further, any visit, interaction or comment will be recorded and visible for the team to review any time of the day.

With each team having a dedicated email group named with the number and title of its chosen project, team members can begin communicating and interacting and working on the project. The instructor tells the students the email group can also act as their virtual meeting room, and its effectiveness can be further enhanced by the other two applications: Microsoft Teams and OneNote. In addition to the three-student team, the instructor will always be the fourth member of each email group, mainly acting in the role of a mentor and facilitator and not a full participant. This must be explained clearly to the students. The specific team members are then added to each email group as per the title they have selected. Students are then given a quick demonstration of how email groups work, including the links with the OneNote and Microsoft Teams applications. Further, upon the creation of each email group, the corresponding team receives an introductory message from the instructor elaborating on some key aspects of the project they will be working on, and encouraging them to start working on some suggested initial tasks.

E-mail groups' features include a calendar for organizing project milestones, a files folder for organizing and storing files and photos, and a platform for on-going conversations. OneNote, a computer program that can function as a running journal, is linked to Microsoft Outlook, and can be accessed through the email group, thus offering each group its own notebook or journal. The notebook or journal-making features are easy to use, and they come with buttons for adding and naming sections as well as adding pages to each section which helps students in developing draft outline that can be continually and incrementally refined and improved upon as the project progresses. OneNote also records the name of each participant every time a task was performed. However, the most important element in the email group is the communication feature. Teams are asked to talk to each other and discuss their project through the email groups as much as it is possible. This way, the instructor, who is also a member in the email group, gets to see the communication, gives feedback when appropriate, and takes note of progress and the degree of activity on the part of each team member. The instructor also gets to see the nature of group dynamics of each team and may intervene to encourage and prompt hesitant or shy students to engage. This can be achieved simply by privately asking for a clarification from such students on a certain topic or aspect of the project.

\section{INSTRUCTOR'S REFLECTION AND STUDENTS' FEEDBACK}

This online, semi-structured approach to helping students make the most of project-based learning, has been used for a total of five semesters, in which the urban and regional planning course was offered five times by the same instructor, and land use planning course three times. Thus, the total number of students who conducted projects using this method was 240 students. At the end of each semester and upon completion of project presentations, an open discussion is conducted where students' experience with the approach is discussed and ways to improve the method are debated. Students are also encouraged to send individual emails to the instructor with any specific feedback that was not discussed or clearly stated in class. One important feedback students repeatedly brought up as a strength of the method is the help they get in starting the project from day one by bypassing the time that could be wasted on trying to agree on a particular project title when the team members still feel less confident in their ability to think of project ideas on their own or because they don't yet know each other fully. Another point of strength had to do with the fact that most students in the program were females who typically commute back to their different cities in the UAE on Wednesday afternoons and return on Saturday afternoons. This has often been an issue when students have little time to meet during school days because of scheduling conflicts, especially when they 
happen to be taking different classes. Thus, the online method not only gave them a platform to meet virtually but also afforded them instant access to the instructor so that they can get feedback and develop confidence in the process as the project progresses. This has meant at time, access to the instructor throughout the day as is the case with online communications. Moreover, the students noted an added benefit and flexibility with the two main apps, Microsoft Outlook and OneNote being accessible through smart phones. Students could be visiting a particular site, taking site pictures, and be able to instantly upload them to the files' folder of the e-mail group while still being physically away from their study space. Overall, these positive aspects helped students streamline their time and response and ensured that they are being mentored consistently by the instructor on almost daily basis which helped them build confidence and enthusiasm.

The instructor has observed that the method proved more effective and allowed for faster communication both among students and between students and instructor. The instructor would visit the email group of each team and would readily spot the level of activity each member is contributing toward the project. Often the instructor's involvement would be as simple as leaving a comment saying "There is good work here. keep it up!". In other instances, the instructor may spot misunderstandings or less coordinated work between the team, in which cases, and without being too critical he would point out the issue and the need for the students to make a decision. It is vital that the instructor does not make choices or decisions for the students, only to provide enough prompts for them to independently feel confident to make their own decisions. Instructor also observed in the first semester this method was tried that almost that a considerable number of students, used the email groups only to upload files and work that was done conventionally. Instructor did not have the chance to review the work with the students as it developed. At first the instructor did not object to students working in this way. However, and upon further observations, the instructor noticed a tendency in the team members to divide the work among themselves to the point that each would be completely focused on the task she worked on without giving any thought or contribution to what the other team members are doing. The result was a disjointed and uncoordinated finished report. This was addressed from the second semester the method was applied by insisting that the students comment on each other's work, and by the instructor reminding the teams that their final report will be graded as if it was completed by one individual. The instructor also noticed a tendency in some students to copy material from the internet without giving it enough thought or without use of proper citation. The method allowed for spotting such issues early on and such students were often notified privately and given ideas on how to avoid falling in such pitfalls. While the author acknowledges that in the first and second trials of this method, he found himself devoting more time than expected in facilitating the active ten email groups, monitoring level of activity and giving feedback, eventually he made it a routine to tell the students that he will pass by each group once every five days. This helped in staggering his involvement and in reducing the overall time dedicated to helping students. It also gave the students a target to work toward that is every four days their activity should be such that it is moving them in the direction of completing the project successfully.

\section{CONCLUSION}

The semi-structured online approach discussed in this article has proved effective in several ways. It has successfully addressed the type of issues and challenges typically faced by both students and instructor when conventionally conducting project-based learning. It has shown that significant benefits and rewarding learning experiences can still be attained by both the students and the instructors through the thoughtful introduction and use of education technology. As confirmed by students, the main strength of this approach resides in its open channels of communication between students and the instructor. More particularly, the approach has helped students connect better with each other and constantly and consistently receive feedback from the instructor. Moreover, the instructor's role as coach and facilitator, as well as his ability to monitor students' performance in real time were greatly enhanced. While this approach was used in the context of students' projects in urban planning courses, its adaptability for use in courses in other disciplines is readily evident. With the rapid changes in education technology and the continuous advancement of online platforms fostering digital learning, the possibilities and potential for further improvement are vast.

\section{REFERENCE LIST}

Aggarwal, P. \& D. O'Brien. (2008). Social Loafing on Group Projects - Structural Antecedents and Effect on Student Satisfaction, Journal of Marketing Education, Vol. 30, Issue:3, pp 255-264.

Belwal, R., Belwal, S., Sufian, A.B. and Al Badi, A. (2020), "Project-based learning (PBL): outcomes of 
students' engagement in an external consultancy project in Oman", Education + Training, Vol. aheadof-print No. ahead-of-print. https://doi.org/10.1108/ET-01-2020-0006

Boyer, R. H. W. (2020). Team-Based Learning in the Urban Planning Classroom. Journal of Planning Education and Research.

Dewey, J. (2008). Experience and Education. SIMON \& SCHUSTER, New York, USA.

Greenlee, A. J., Edwards, M., \& Anthony, J. (2015). Planning Skills: An Examination of Supply and Local Government Demand. Journal of Planning Education and Research, 35(2), 161-173.

Ives-Dewey, D. (2009). "Teaching Experiential Learning in Geography: Lessons from Planning." Journal of Geography 107 (4-5): 167-74.

Johnson, D., Johnson, R., \& Smith, K. (2014). Cooperative learning: improving university instruction by basing practice on validated theory. Journal on Excellence in College Teaching, 25(3\&4), 85-118.

Konrad, T., Wiek, A. and Barth, M. (2020), "Embracing conflicts for interpersonal competence development in project-based sustainability courses", International Journal of Sustainability in Higher Education, Vol. 21 No. 1, pp. 76-96. https://doi.org/10.1108/IJSHE-06-2019-0190

Kotval, Z. (2003). "Teaching Experiential Learning in the Urban Planning Curriculum." Journal of Geography in Higher Education 27 (3): 297-308.

Long, J. G. (2012). State of the Studio: Revisiting the Potential of Studio Pedagogy in U.S.-Based Planning Programs. Journal of Planning Education and Research, 32(4), 431-448.

Michaelsen, L. K., Sweet, M. (2008). "The Essential Elements of Team-Based Learning." In Team-Based Learning: Small Group Learning's Next Big Step, edited by Michaelsen, Larry K., Sweet, Michael, Parmelee, Dean X.1-28. San Francisco: Jossey-Bass.

Neu, W. (2012). Unintended cognitive, affective, and behavioral consequences of group assignments. Journal of Marketing Education, 34(1), 67-81.

Ozawa, C., \& Seltzer, E. (1999). Taking Our Bearings: Mapping a Relationship among Planning Practice, Theory, and Education. Journal of Planning Education and Research, 18(3), 257-66.

Schon, D. (1983). The Reflective Practitioner. INGRAM PUBLISHER SERVICES US, New York, USA

Shepherd, A., \& Cosgriff, B. (1998). Problem-based Learning: A Bridge between Planning Education and Planning Practice. Journal of Planning Education and Research 17 (4), 348-357.

Sherrard, W., Raafat, F., \& Weaver, R. (1994). An Empirical study of peer bias in evaluations: Students rating students. Journal of Education for Business, 70, 43-48.

Susskind, Lawrence, Ozawa, Connie.1984. "Mediated Negotiation in the Public Sector: The Planner as Mediator." Journal of Planning Education and Research 4 (1):5-15. 